\title{
The Application of BIM to Project Cost Management
}

\author{
lina $\mathrm{Ha}^{1}$ \\ ${ }^{1}$ Urumqi Vocational University
}

\begin{abstract}
Nowadays among numerous industries that are undergoing continuous development along with China's rapid economic growth is the noticeable one, building or construction industry. A building or construction project is composed of many parts, including project costs. This paper presents a basic introduction of the BIM technology, project cost management and the latter's importance. On the basis of that and practical cases, the application of BIM to project cost management is analyzed and its advantages are summarized.
\end{abstract}

\section{Introduction}

The constant development of China's technologies since the reform and opening up can be seen from the fact that many are applied to a variety of industries and are becoming increasingly mature as the time advances. BIM is a technology that so far has been applied to a quantity of industries after the period of time from its embryonic to mature stage, especially in project cost management. It is well known that project cost management is critical in a project and even directly linked to the costs and economic benefits. This paper studies the application of BIM to project cost management.

\section{The Outline of BIM}

Recent years has seen the application and contributions of BIM to various industries. The so-called BIM is a model established on the basis of diverse kinds of information. Its theory initially appeared in America in the nineteen sixties, while its thought originated in the nineteen seventies with the appearance and development of CAD technology. During the following ten years, it shifted from textbooks to practice, which marked a new beginning that BIM started to help people resolve problems occurring in practice. The BIM technology gathers all kinds of available information pertaining to a specific project so as to construct a simulated model of the building. All the subsequent management can be realized through threedimensional models. That is what we call the BIM technology ${ }^{[1]}$. BIM is not merely the generally regarded software similar to CAD that appears favorable to builders and construction sides. It more importantly serves as a pool of the digitalized information of relevance to a certain construction project, and a carrier that works to store and share related knowledge resources, which can be added, extracted or updated in real time at any time of the different project stages so that relevant staff are enabled to complete their respective work and perform their functions with its timely aid. The BIM technology has been applied to cost management in many projects in recent years, rendering cost management less difficult and more accurate to some extent.

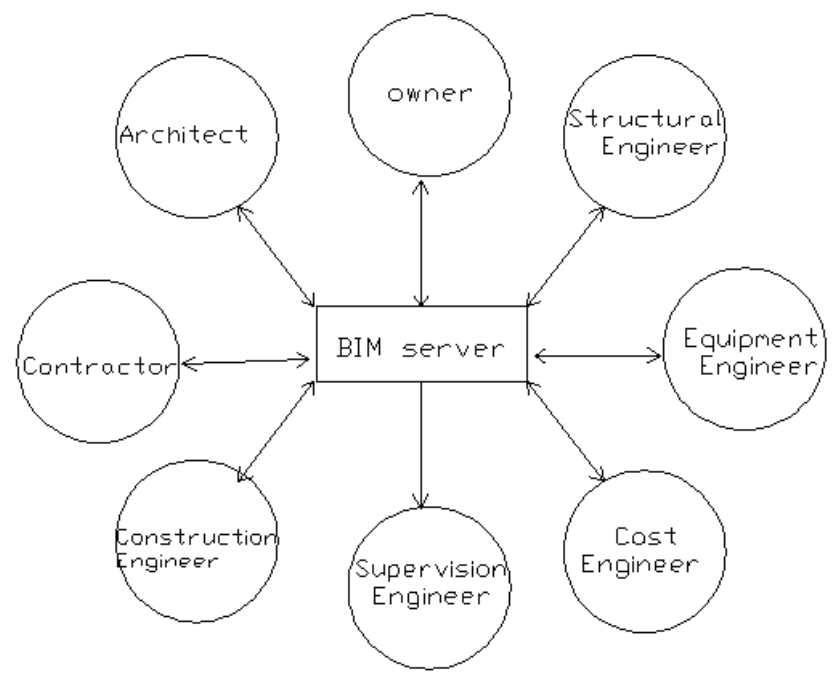

\section{The Contents and Importance of Project Cost Management}

At present project cost management is indispensable in virtually all kinds of projects in China, for instance, the constructional engineering of residential, commercial and government buildings, schools and hospitals, and airports and wharfs. The generally so-called construction project costs are the estimated or actual expenses paid for a whole project, which contains construction and installation price incurred in the transaction activities in equipment, technology and labor markets, and the total price of this construction project. Project costs in a sense amount to the price of this project. At present China possesses a wide range of knowledge and technologies that can be used to 
estimate, analyze, control, audit and evaluate construction project costs, among which the BIM technology is playing a vital role in project cost management. Project costs basically contain: all the expenses that a certain construction entity incurs, including labor, raw materials and equipment expenses; indirect expenses, for instance, all the administrative and testing expenses; profit after completion; all taxes; other expenses involved in a project.

The work of project costs is critical in the whole process of a project ${ }^{[2]}$. First of all, it is effective to control the cost of a project and is directly linked to the economic benefits gained eventually. Project cost management can prevent corruption occurring in the process of a project, and have a direct influence on project quality. Only when project costs incurred in every link are controlled reasonably, can the project generate more social benefits to the public and economic ones to its investors.

\section{The Application of BIM to Project Cost Management}

The BIM technology has been widely applied to cost management in numerous projects in recent years. Its main functions comprise: examining design drawings and construction documentation; using BIM technology to consolidate and collect the quantitative changes in a project so as to perform cost management; updating BIM models on the real-time changes taking place in a project, evaluating and sharing the real-time information on collaborative management platforms, and settling project costs. This paper introduces the application of BIM to project cost management from the above-mentioned aspects respectively.

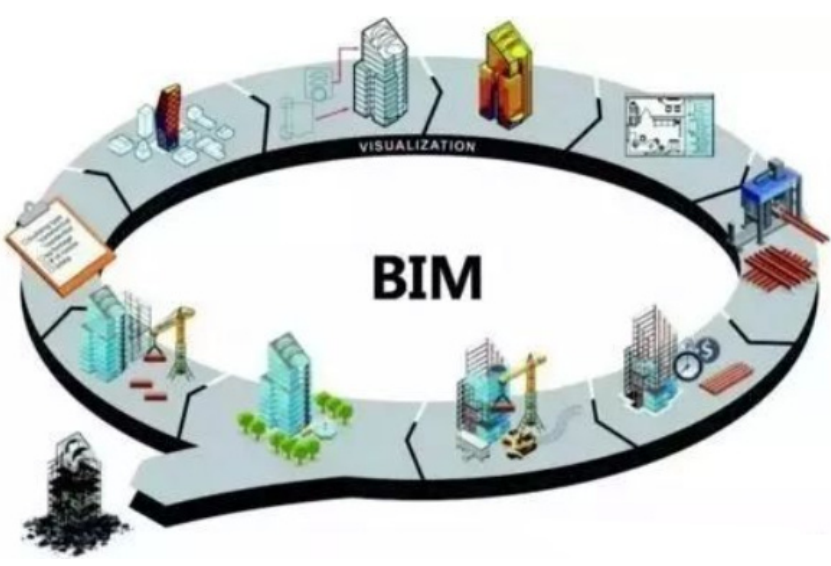

\subsection{The application of BIM to cost management at the preliminary stage of a project}

The work at the preliminary stage of a project principally contains decision, design and bidding, which exist at the initial stage of any project, while the costs of a certain project are of dependence on the target set in the decision period. At this stage, BIM constructs simulated models of the entire project through multi-dimensional modeling, including three-dimensional modeling, project schedule, and the analysis and classification of construction costs. Afterwards the estimation and statistics based on data presented in these models work to facilitate project cost management ${ }^{[3]}$. The impact imposed by design on project costs varies from $35 \%$ to $75 \%$. The depth of design requirements and the detail level for documentation both exert direct effect on the accuracy of design budgetary estimate. Before onerous and complicated design and incomplete documentation tended to result in calculation errors, whereas in the times of BIM, high-accuracy documentation of project quantity can be quickly accessed simply by importing the modified BIM models established in the investment and decision period with the aid of corresponding quantity surveying software. Moreover, 4D-BIM models established after adding time dimension contribute to the gradual deepening of design, and the virtual construction that is performed by designers in order to refine their technology design and minimize subsequent potential risks as much as possible.

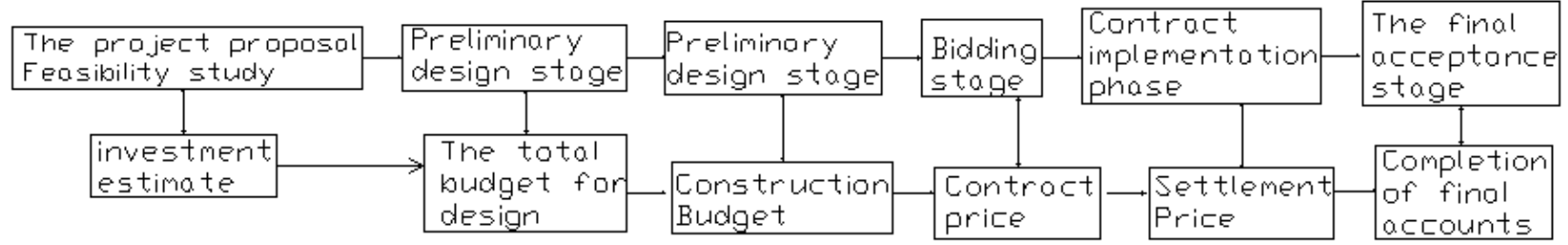

(Schematic diagram of construction stages and corresponding estimate and budget)

\subsection{The application of BIM to cost management at the construction stage of a project}

A quantity of work is also involved in project cost management at the construction stage of a project. Above all, managers must be acquainted with their project contracts and implement effective management so as to remain well prepared for the payment and changes of project funds, and minimize engineering claims.
Additionally, project costs can be controlled from the delivery of technologies and engineering materials. Finally, the price of engineering materials must be maintained at a reasonable level despite its monthly and even daily variances in the ever-changing market, which requires staff responsible for project cost management to conduct surveys in advance of the prices of materials needed in the entire construction period, and real-time surveys at construction stage to gather information. One of the most striking characteristics possessed by the BIM 
technology proves the visualization and informatization displayed by its models, which appears more specific with more information, and keeps updated in sync with the latest information. The project models established by using the BIM technology are possible to have their overall information updated in line with construction schedules at any time. The high consistency between construction buildings and building models significantly reduces subsequent surveys on practical project. The timeliness met by all the information saves cost personnel many unnecessary troubles. At this stage the BIM technology contributes to the earlier detection of problems hidden or exposed in project cost management ${ }^{[4]}$. For instance, some unnecessary expenditure immune from manual inspection during project construction can be detected in time by applying the BIM technology to cost management so as to reduce project expenditure. Moreover, statistics reveal that BIM plays an irreplaceable role in cost management since the total project cost can attain $70 \%$ benefits at a cost of $3 \%$ expenses on the BIM technology. Management staff are required to consolidate and selectively output database information, drawings and design costs before providing necessary information for management.



(Decline in proportion of unpredictable costs benefiting from the application of BIM)

\subsection{The application of BIM to cost management at post-project stage}

Project costs after completing construction remain the final but indispensable stage in project cost management. Relevant staff are required to present a holistic picture of the project costs incurred in a whole construction on the basis of summarizing related contracts and agreements drawn up previously, estimated costs and expenses, and materials needed for local government and other related organizations ${ }^{[5]}$. The application of BIM to project cost management in this period can significantly improve accuracy and efficiency. BIM is a technology that possesses its own big database, in which all the project contents involved in a certain construction are allowed to be assembled. Its informatized database can share information collaboratively with project cost management platforms.

\section{Advantages of BIM's Application to Project Cost Management}

BIM is a modern technology that possesses huge advantages when applied to project cost management. Firstly, the BIM technology can share with project cost management staff at the earliest time the latest information constantly updated in sync with the real-time changes in a project. The BIM technology can gather and convey the updated information to staff in time, which is effective to address the issue that traditional project cost management is delayed mostly due to belated information. Moreover, its application generates optimal project cost management. The essence of project costs proves the controlling of construction quality and costs. The BIM technology is a tool based on informatized models that appear superior in assisting engineering staff to conduct the most optimized management. Lastly, it makes each part of project cost management fair-grained and well-grounded when applied to project costs. Different projects vary in their specific conditions. Unlike traditional project cost management that presents estimated price by referring to previous practical cases or experience, the BIM technology estimates the total price reasonably based on the specific expenses required for each part of the entire project quantity. 



(BIM virtual collision check)

\section{Conclusion}

Currently China's BIM technology still remains in the initial stage, more or less facing some problems, on which continuous studies is of benefit to promote the development of both this technology and related industries in China. The BIM technology has been widely applied to all stages of project cost management. This increasingly mature technology is favorable to facilitate project cost management and vice versa. It is well known that project costs play a vital role in controlling costs and maximizing economic benefits. In consequence, to impose a reasonable control on project costs remains critical in an entire construction project. Therefore, the BIM technology should be applied to the whole process of a construction project for cost management, which contributes to the controlling of the whole project and the obtaining of desired economic benefits.

\section{References}

1. Jamie Bull, Akshay Gupta, Dejan Mumovic, Judit Kimpian. Life cycle cost and carbon footprint of energy efficient refurbishments to 20th century UK school buildings[J].International Journal of Sustainable Built Environment.2014.31.

2. Anni Lindholm, Petri Suomala. Learning by costing: Sharpening cost image thro-ugh life cycle costing[J]. International Journal of Productivity and Performance Ma-nagement.2007.568.

3. Vahida Zujo,Diana Car-Pusic,Valentina ZileskaPancovska. Cost and Experience based Real Estate Estimation Model[J]. Procedia - Social and Behavioral Sciences.2014.119. 